\title{
Near-Infrared Spectroscopy Measured Cerebral Blood Flow from Spontaneous Oxygenation Changes in Neonatal Brain Injury
}

\author{
Gemma Bale, Nathan Taylor, Subhabrata Mitra, Aleh Sudakou, \\ Isabel de Roever, Judith Meek, Nicola Robertson, and Ilias Tachtsidis
}

\begin{abstract}
Neonates with hypoxic-ischaemic (HI) brain injury were monitored using a broadband near-infrared spectroscopy (NIRS) system in the neonatal intensive care unit. The aim of this work is to use the NIRS cerebral oxygenation data (HbD = oxygenated-haemoglobin - deoxygenated-haemoglobin) combined with arterial saturation $\left(\mathrm{SaO}_{2}\right)$ from pulse oximetry to calculate cerebral blood flow (CBF) based on the oxygen swing method, during spontaneous desaturation episodes. The method is based on Fick's principle and uses HbD as a tracer; when a sudden change in $\mathrm{SaO}_{2}$ occurs, the change in $\mathrm{HbD}$ represents a change in tracer concentration, and thus it is possible to estimate CBF. CBF was successfully calculated with broadband NIRS in 11 HIE infants ( 3 with severe injury) for 70 oxygenation events on the day of birth. The average CBF was $18.0 \pm 12.7 \mathrm{ml} 100 \mathrm{~g}^{-1} \mathrm{~min}^{-1}$ with a range of $4 \mathrm{ml} 100 \mathrm{~g}^{-1} \mathrm{~min}^{-1}$ to $60 \mathrm{ml} 100 \mathrm{~g}^{-1} \mathrm{~min}^{-1}$. For infants with severe HIE (as determined by magnetic resonance spectroscopy) CBF was significantly lower ( $\mathrm{p}=0.038, \mathrm{~d}=1.35)$ than those with moderate HIE on the day of birth.
\end{abstract}

Keywords Near-infrared spectroscopy $\cdot$ Cerebral blood flow $\cdot$ Neonatal brain injury $\cdot$ Hypoxic-ischaemic encephalopathy $\cdot$ Clinical

G. Bale $(\triangle) \cdot$ N. Taylor $\cdot$ I. de Roever $\cdot$ I. Tachtsidis

Medical Physics and Biomedical Engineering, University College London, London, UK

e-mail: g.bale@ucl.ac.uk

S. Mitra $\cdot$ J. Meek $\cdot$ N. Robertson

Institute for Women's Health, University College London, London, UK

A. Sudakou

Nalecz Institute of Biocybernetics and Biomedical Engineering, Polish Academy of Sciences,

Warsaw, Poland 


\section{Introduction}

Hypoxic ischaemic encephalopathy (HIE), which affects 1-2 full term newborns per 1000, is associated with severe neurodevelopmental problems and is the third leading cause of global child deaths [1]. HIE is an evolving process; after ischaemia during the injury, the brain is reperfused but the cerebral blood flow (CBF) can fluctuate between hypo-and hyper-perfusion in the first days after birth, and in some cases the injury can progress into a secondary energy failure [1]. Strategies to treat HIE focus on the maintenance of cerebral perfusion and preventing the cascade of events leading to further brain injury.

We have previously presented a broadband NIRS device called CYRIL (CYtochrome Research Instrument and appLication) to monitor cerebral haemodynamics and metabolism via cytochrome-c-oxidase in the newborn brain [2]. In this paper, we present a method to additionally monitor CBF changes with CYRIL in neonates with HIE. Previously, researchers have used NIRS to measure CBF by using the oxygen swing method; oxygenation changes in the brain can be used to calculate the CBF via Fick's law [3]. This states that the quantity of substance taken up by an organ per unit time $(\mathrm{dQ} / \mathrm{dt})$ is equal to the rate of arrival of the substance to an organ (arterial concentration $\left(\mathrm{C}_{\mathrm{a}}\right)$ multiplied by the blood flow $(\mathrm{F})$ ), minus the rate of departure from the organ (venous concentration $\left(\mathrm{C}_{\mathrm{v}}\right)$ multiplied by $\mathrm{F}$ ):

$$
d Q / d t=F\left(C_{a}-C_{v}\right)
$$

If $\mathrm{Q}$ varies with time, then this equation can be integrated with respect to time to obtain blood flow in terms of the quantity of tracer within the organ, and its arterial and venous concentrations:

$$
F=Q / \int\left(C_{a}-C_{v}\right) d t
$$

$\mathrm{Q}$ is equivalent to the product of the concentration of tracer in the tissue $\left(\mathrm{C}_{\mathrm{T}}\right)$ and the unit weight of the tissue (W). This relationship can be used to obtain CBF in the more commonly used units, $\mathrm{ml}$ per $100 \mathrm{~g}$ of brain tissue per minute. Furthermore, if the accumulation is measured within the minimum transit time of the organ, reported as around $8 \mathrm{~s}$ for the brain in neonates [4], then the venous concentration of the substance will be zero. CBF can then be calculated from the ratio of the tracer accumulated to the quantity of tracer introduced during time $t$ :

$$
F / W=C_{\mathrm{T}} / \int C_{a}(t) d t=C B F
$$

When applied to NIRS measurements of CBF, the arterial concentration of substance introduced over time $\mathrm{t}$ can be represented by the integral of the change in fractional arterial oxygen saturation $\left(\mathrm{SaO}_{2}\right)$ multiplied by the total concentration of haemoglobin in the blood. The accumulation of substance in the organ becomes the concentration of oxy-haemoglobin $\left(\mathrm{HbO}_{2}\right)$ in the brain, measured by NIRS, and $\mathrm{CBF}$ is then obtained from the equation: 


$$
C B F=K \cdot \Delta\left[\mathrm{HbO}_{2}\right] /\left[t \mathrm{Hb} \cdot 10^{-2}\right] \cdot \int \Delta \mathrm{SaO}_{2} d t
$$

with

$$
K=M W H b \cdot 10^{-2} / D t \cdot 10
$$

where $\mathrm{MW}_{\mathrm{Hb}}$ is the molecular weight of haemoglobin $\left(64,500 \mathrm{~g} \mathrm{~mol}^{-1}\right), \mathrm{tHb}$ is the total haemoglobin concentration, and Dt is the tissue density, assumed to be 1.05 g.ml ${ }^{-1}$ in the brain [3].

Haemoglobin difference $\left(\mathrm{HbD}=\mathrm{HbO}_{2}-\mathrm{HHb}\right)$ is a measure of oxygen delivery that has a larger amplitude (and thus higher signal to noise) and is also more stable than either of the two individual signals as artefacts are subtracted. If total haemoglobin concentration remains stable throughout the measurement, the change in $\mathrm{HbD}$ can be expressed as twice the change in $\mathrm{HbO}_{2}$ and therefore $\mathrm{CBF}$ is:

$$
C B F=K \cdot \Delta[H b D] / 2\left[t H b \cdot 10^{-2}\right] \cdot \int \Delta S a O_{2} d t
$$

Here we demonstrate the use of this method not with controlled oxygen challenges, but on spontaneous desaturation events in newborns with brain injury undergoing intensive care. This allows non-invasive measurements of CBF at the cot side without intervention.

\section{Methods}

\subsection{Data Collection}

Ethical approval for the Baby Brain Study at University College London Hospitals (UCLH) Trust, London was obtained from the North-West Research Ethics Centre (REC reference: 13/LO/0106). Term infants born at or transferred to UCLH for treatment of acute brain injury were eligible for investigation; infants with congenital malformations were excluded. Informed consent was obtained before each study. Each subject was monitored continuously with EEG and treated with hypothermia which was initiated within 6 hours of birth; body temperature was lowered to $33.5^{\circ} \mathrm{C}$ and was maintained for 72 hours before gradual rewarming.

Broadband NIRS measurements were collected with CYRIL continuously over a period ranging from 1-15 hours on the first day of life during therapeutic hypothermia. NIRS probes were placed over the left-side of the forehead (covering the left frontal lobe) with $3 \mathrm{~cm}$ optode separation and with a sampling frequency of $1 \mathrm{~Hz}$. Changes in chromophore concentrations $\left(\mathrm{HbO}_{2}, \mathrm{HHb}\right.$, and the oxidation state of cytochrome-coxidase, oxCCO) were calculated from the measured changes in light attenuation using the modified Beer-Lambert law. This was applied across 770-906 nm with a differential pathlength factor of 4.99 [5], which is corrected for the pathlength wavelength-dependency. Examples of obtained intensity spectra are published in Bale et al. [2]. 
Systemic data from the Intellivue Monitors (Philips Healthcare, UK) were collected using ixTrend (ixellence $\mathrm{GmbH}$, Germany). Signals recorded include oxygen saturation $\left(\mathrm{SaO}_{2}\right)$ measured by pulse oximetry, heart rate (HR), respiratory rate (RR), and mean arterial blood pressure (MABP).

An MRI scan was performed after rewarming; this occurred on average on day 7 of life (range: day 5-15). MR scans included a measurement of thalamic Lac/NAA with proton $\left({ }^{1} \mathrm{H}\right)$ magnetic resonance spectroscopy (MRS); Lac/NAA score $\geq 0.3$ has been shown to be associated with poor outcome [6].

\subsection{Data Analysis}

Data analysis was carried out in MATLAB (Mathworks, USA). Systemic data were down-sampled and interpolated to the NIRS data timeframe $(1 \mathrm{~Hz})$. Changes in $\mathrm{SaO}_{2}$ of $2 \%$ or greater occurring in under 7 seconds (determined to be the transit time of the brain) were identified manually using a graphical user interface written in-house. Events were rejected if the initial $\mathrm{SaO}_{2}$ was less than $70 \%$, if there was a change in HR or RR of more than $10 \mathrm{bpm}$ during the event, or if the HbD standard deviation was greater than $1 \mu \mathrm{M}$ in the 10 s before the event. An example of the pulse oximetry and broadband NIRS data used is shown in Fig. 1a and b). The gradient of the change in $\mathrm{HbD}$ and integral of $\mathrm{SaO}_{2}$ with respect to time during the first $7 \mathrm{sec}$ onds of the event was used to calculate the CBF (see Fig. 1c) and Eq. 6). Data are presented as median and confidence interval, and statistical significance was assessed with the Mann-Whitney $U$ test ( $p>0.05$ is significant) and the effect size was tested by Cohen's $d(d>1.2$ is 'very large') [7].

(a)

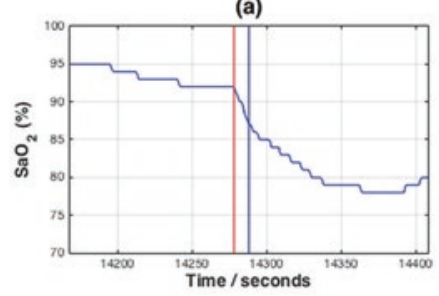

(b)

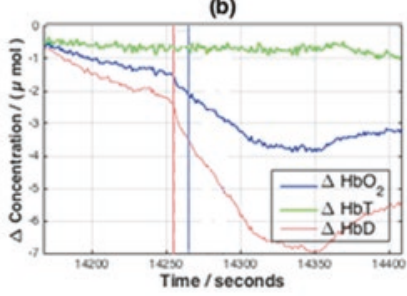

(c)

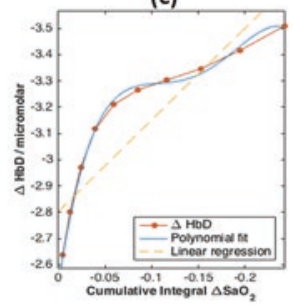

Fig. 1 Example of the CBF calculation method: (a) $\mathrm{SaO}_{2}$ and (b) $\mathrm{HbD}$. The vertical lines indicate the region of interest (10 seconds) used for the calculation. (c) The change in $\mathrm{HbD}$ plotted against the equivalent cumulative change in $\mathrm{SaO}_{2}$ integral; with a fitted fourth order polynomial and a fitted linear regression. The $\mathrm{CBF}$ in this event is $22.1 \mathrm{ml} 100 \mathrm{~g}^{-1} \mathrm{~min}$ 


\section{Results}

CBF was calculated during 42 desaturation episodes noted in 11 infants with HIE on the day of birth. Of these infants, 3 were predicted to have a poor outcome by the MRS Lac/NAA biomarker. See Table 1 for clinical details, number of events and mean CBF for each neonate. The mean gestational age was $39.3 \pm 1.2$ weeks and the mean birth weight was $3262 \pm 334 \mathrm{~g}$. The median CBF was $12 \mathrm{ml} 100 \mathrm{~g}^{-1} \mathrm{~min}^{-1}$ with a range of $4 \mathrm{ml} 100 \mathrm{~g}^{-1} \mathrm{~min}^{-1}$ to $60 \mathrm{ml} 100 \mathrm{~g}^{-1} \mathrm{~min}^{-1}$. For infants with severe HIE, CBF was lower $\left(8.5(6.5-11.0) \mathrm{ml} 100 \mathrm{~g}^{-1} \mathrm{~min}^{-1}\right)$ than moderate HIE infants (15.2 (4.0-60.0) $\left.\mathrm{ml} 100 \mathrm{~g}^{-1} \mathrm{~min}^{-1}\right)$ on the day of birth $(\mathrm{p}=0.038, \mathrm{~d}=1.35$, see Fig. 2$)$.

\section{Discussion}

The NIRS measured CBFs are in line with those previously measured in newborns by the oxygen swing technique [4, 8], Xenon clearance [4, 9], dynamic contrastenhanced NIRS with indocynanine green [10] and phase contrast MRI [11] which had means of 29.7 (range 11.4-62.1), 11.7 (range 5-26.1), 14.8 (range 5.1-30.4),

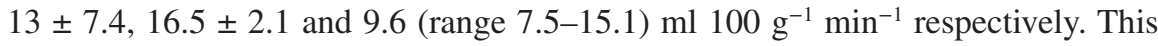
suggests that using the oxygen swing method on spontaneous desaturation events is a feasible way to measure $\mathrm{CBF}$ without intervention.

Neonates with severe HIE experienced hypoperfusion on the first day of life. This is consistent with a finding from an MRI arterial spin labelling study; infants with severe HIE had significantly lower CBF on the first two days of life than those with moderate HIE [12]. The decreased CBF in more severe injury could be caused by evolving pathophysiology of HIE - following HI, there is a period of hypoperfusion

Table 1 Clinical details and number of eligible desaturation events for neonates included. Unfavourable outcome was determined by MRS Lac/NAA $>0.3$. Birth weight measured in grams, CBF measured in $\mathrm{ml} 100 \mathrm{~g}^{-1} \mathrm{~min}^{-1}$

\begin{tabular}{l|l|l|l|l|l|l|l}
\hline Neonate & Gender & $\begin{array}{l}\text { GA } \\
\text { (weeks) }\end{array}$ & $\begin{array}{l}\text { Birth } \\
\text { weight }\end{array}$ & Lac/NAA & $\begin{array}{l}\text { Injury } \\
\text { outcome }\end{array}$ & No. of events & CBF \\
\hline 3 & F & 41.0 & 3800 & 0.2 & Favourable & 2 & $14 \pm 4$ \\
\hline 9 & M & 38.9 & 2850 & 0.16 & Favourable & 6 & $10 \pm 1$ \\
\hline 11 & F & 40.6 & 3580 & 0.08 & Favourable & 12 & $16 \pm 5$ \\
\hline 14 & M & 37.7 & 3750 & 0.25 & Favourable & 4 & $47 \pm 10$ \\
\hline 15 & F & 39.6 & 3240 & 0.15 & Favourable & 9 & $11 \pm 4$ \\
\hline 17 & F & 37.4 & 3160 & 0.35 & Unfavourable & 2 & $7 \pm 1$ \\
\hline 33 & F & 38.4 & 2900 & 0.43 & Unfavourable & 4 & $9 \pm 2$ \\
\hline 35 & F & 38.7 & 3150 & 0.14 & Favourable & 4 & $21 \pm 11$ \\
\hline 37 & F & 39.4 & 3330 & 0.2 & Favourable & 2 & $41 \pm 2$ \\
\hline 56 & M & 40 & 3365 & 0.34 & Unfavourable & 1 & $11 \pm 0$ \\
\hline 60 & F & 40.7 & 2754 & 0.15 & Favourable & 3 & $12 \pm 3$ \\
\hline
\end{tabular}




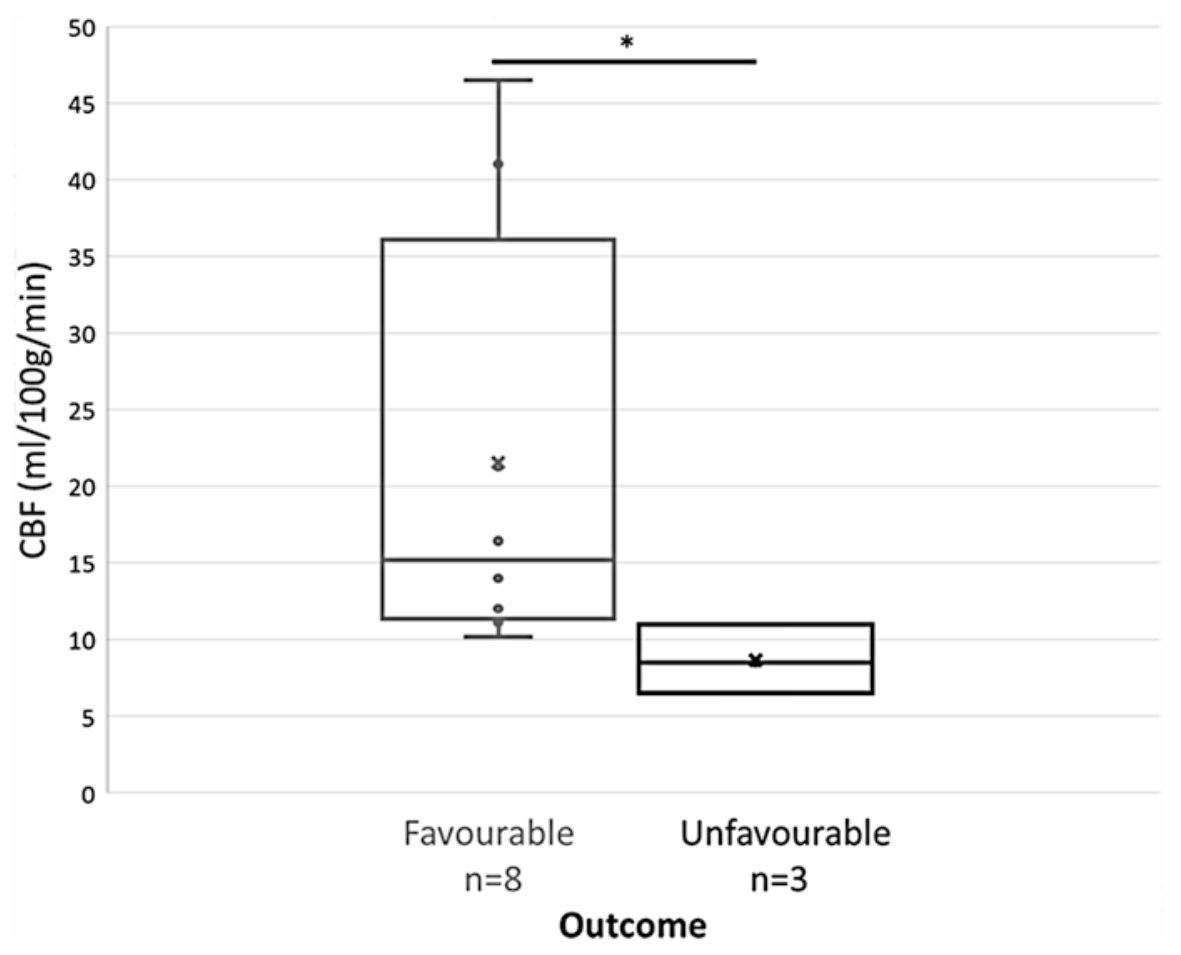

Fig. 2 Boxplot of CBF on first day of life per injury severity group $(* \mathrm{p}=0.024)$

associated with hypometabolism during the latent phase, followed by relative hyperperfusion in the secondary phase [1].

Therapeutic hypothermia itself can reduce $\mathrm{CBF}$; an index of $\mathrm{CBF}$ measured by diffuse correlation spectroscopy has been shown to be reduced during cooling compared to after rewarming in a HIE group, as well as compared to a control group at normothermia [13]. However, this cannot account for the differences in CBF between the injury severity groups because all neonates were being treated with hypothermia during the measurement. It important to be aware of the impact of cooling on $\mathrm{CBF}$, as an early study without hypothermia showed the opposite trend; there was a trend for higher CBF in infants with severe HIE [8]. This observation of hypoperfusion solely in the severe group suggests that the temporal progression of injury and/or the response to treatment is injury dependent.

We have demonstrated a method of calculating absolute CBF non-invasively and without any intervention using NIRS during spontaneous hypoxic events in HIE infants. This technique is advantageous because it can be performed at the cot side and does not require any intervention, but is limited because the spontaneous nature of the events. Indeed, desaturation episodes are not guaranteed in all infants during a study period. However, we could identify a difference in the level of perfusion between neonates with moderate and severe injury on the first day of life. This suggests that monitoring CBF during HIE will give important clinical information that may have further prognostic value. 
Acknowledgments The authors would like to thank the parents who gave consent for their children to participate. This research was funded by The Wellcome Trust (1004580/Z/14/Z). NR, SM and JM acknowledge the support of the UCLH Biomedical Research Centre.

\section{References}

1. Hassell KJ, Ezzati M, Alonso-Alconada D, Hausenloy DJ, Robertson NJ (2015) New horizons for newborn brain protection: enhancing endogenous neuroprotection. Arch Dis Child Fetal Neonatal Ed 100(6):F541-F552

2. Bale G, Mitra S, Meek J, Robertson N, Tachtsidis I (2014) A new broadband near-infrared spectroscopy system for in-vivo measurements of cerebral cytochrome-c-oxidase changes in neonatal brain injury. Biomed Opt Express 5(10):3450-3466

3. Elwell CE, Cope M, Edwards AD, Wyatt JS, Reynolds EO, Delpy DT (1992) Measurement of cerebral blood flow in adult humans using near infrared spectroscopy--methodology and possible errors. Adv Exp Med Biol 317(4):235-245

4. Skov L, Pryds O, Greisen G (1991) Estimating cerebral blood flow in newborn infants: comparison of near infrared spectroscopy and 133Xe clearance. Pediatr Res 30(6):570-573

5. Duncan A et al (Feb. 1995) Optical pathlength measurements on adult head, calf and forearm and the head of the newborn infant using phase resolved optical spectroscopy. Phys Med Biol 40(2):295-304

6. Thayyil S et al (2010) Cerebral magnetic resonance biomarkers in neonatal encephalopathy: a meta-analysis. Pediatrics 125(2):e382-e395

7. Sawilowsky SS (2009) New effect size rules of thumb. J Mod Appl Stat Methods 8:597-599

8. Meek J, Elwell C (1999) Abnormal cerebral haemodynamics in perinatally asphyxiated neonates related to outcome. Arch Dis Child 81:F110-F115

9. Pryds O, Edwards AD (1996) Cerebral blood flow in the newborn infant. Arch Dis Child 74:F63-F69

10. Diop M, Tichauer KM, Elliott JT, Migueis M, Lee T-Y, St Lawrence K (2015) Comparison of time-resolved and continuous-wave near-infrared techniques for measuring cerebral blood flow in piglets. J Biomed Opt 15(5):057004

11. Jain V et al (2013) Cerebral oxygen metabolism in neonates with congenital heart disease quantified by MRI and optics. J Cereb Blood Flow Metab 34(3):380-388

12. Wintermark P, Hansen A, Warfield SK, Dukhovny D, Soul JS (2014) Near-infrared spectroscopy versus magnetic resonance imaging to study brain perfusion in newborns with hypoxicischemic encephalopathy treated with hypothermia. Neuroimage 85(1):287-293

13. Dehaes M et al (2014) Cerebral oxygen metabolism in neonatal hypoxic ischemic encephalopathy during and after therapeutic hypothermia. J Cereb Blood Flow Metab 34(1):87-94

Open Access This chapter is licensed under the terms of the Creative Commons Attribution 4.0 International License (http://creativecommons.org/licenses/by/4.0/), which permits use, sharing, adaptation, distribution and reproduction in any medium or format, as long as you give appropriate credit to the original author(s) and the source, provide a link to the Creative Commons license and indicate if changes were made.

The images or other third party material in this chapter are included in the chapter's Creative Commons license, unless indicated otherwise in a credit line to the material. If material is not included in the chapter's Creative Commons license and your intended use is not permitted by statutory regulation or exceeds the permitted use, you will need to obtain permission directly from the copyright holder. 